\title{
Polymorphic repetitive loci of the amphibian pathogen Batrachochytrium dendrobatidis
}

\author{
Stephen Garland ${ }^{1, *}$, Timothy Y. James ${ }^{2}$, David Blair ${ }^{3}$, Lee Berger ${ }^{1}$, Lee F. Skerratt ${ }^{1}$ \\ ${ }^{1}$ Amphibian Disease Ecology Group, and the School of Public Health, Tropical Medicine and Rehabilitation Sciences, \\ James Cook University, Townsville, Queensland 4811, Australia \\ ${ }^{2}$ Department of Ecology and Evolutionary Biology, University of Michigan, Ann Arbor, Michigan 48109-1048, USA \\ ${ }^{3}$ School of Marine and Tropical Biology, James Cook University, Townsville, Queensland 4811, Australia
}

\begin{abstract}
Batrachochytrium dendrobatidis $(B d)$, the cause of a fatal fungal skin disease of amphibians that has led to massive die-offs, global declines and extinctions, has spread internationally as a pandemic clone with low genetic diversity. A need exists to develop highly polymorphic markers to determine centers of origin and patterns of spread to assist in the development of management strategies. Comparison of paralogous sequences, obtained from the 2 sequenced $B d$ genomes, indicates useful levels of inter-strain polymorphism in repetitive fragments. We assessed 6 repetitive loci for variation within and among Australian isolates using standard fragment analysis and capillary electrophoresis-single strand conformation polymorphism (CE-SSCP) analysis. Confirmation of inter-isolate polymorphism was achieved for 2 marker systems, highlighting the potential of repetitive loci for the development of polymorphic markers in $B d$. In addition, we found that repetitive loci in $B d$ include possible orthologs of virulence-related genes from pathogenic fungi.
\end{abstract}

KEY WORDS: Batrachochytrium dendrobatidis $\cdot$ Chytrid $\cdot$ Molecular strain typing $\cdot$ SSCP

\section{INTRODUCTION}

The fungus Batrachochytrium dendrobatidis $(B d)$, the cause of a fatal skin disease of amphibians (chytridiomycosis), has rapidly spread worldwide causing massive die-offs leading to global declines and extinctions (Pounds et al. 2006, Skerratt et al. 2007). Knowledge of the epidemiology and strain diversity of $B d$ are needed in order to determine the geographic and host origin of the disease and mode(s) of spread and to assist in the development of effective biosecurity procedures, a necessity in the management of global amphibian trade (Skerratt et al. 2007).

The pandemic form of $B d$ appears to have recently emerged as a lineage of closely related diploid genotypes (Morehouse et al. 2003, Morgan et al. 2007, James et al. 2009). Consequently, it has proven difficult to develop marker systems possessing enough polymorphism to identify distinct strains that might be associated with pathogenicity, geographic regions or amphibian species, and to identify centres of diversity and examine the possibility of gene flow.

Morehouse et al. (2003) found low levels of polymorphism and only 3 variable nucleotide positions in 10 gene regions (5918 bp), developed from random genomic clones across $35 B d$ isolates from North and Central America, Africa and Australia. Morgan et al. (2007) searched approximately $20 \%$ of the $B d$ genome (genome size estimated at $23.7 \mathrm{Mb}$ ) for microsatellite sequences, but these were both rare and short. The 12 polymorphic loci found 76 loci screened) each possessed only 2 alleles, thus severely limiting the ability to differentiate closely related genotypes. Similarly, James et al. (2009) found no more than 2 alleles per locus in their survey of sequence variation at 17 nuclear loci from $59 B d$ strains from the Americas, Africa, Australia and Europe. 
In many taxa the mitochondrial genome and the nuclear ribosomal DNA cluster are sources of useful markers. Morgan et al. (2007) and James et al. (2009) found that mitochondrial DNA was highly conserved in Bd. Morgan et al. (2007) suggested that ribosomal DNA internal transcribed spacer (ITS) sequence possessed too much intra-individual variation to be useful. In contrast, Goka et al. (2009) successfully identified 26 haplotypes for an approximately 300 bp fragment of the ITS region in their assessment of 2662 captive and wild Japanese amphibians.

Our preliminary assessment of 5 cultured Australian isolates found no variation in an ITS1 fragment (S. Garland unpubl.), a fragment possessing most of the genetic variation found by Goka et al. (2009). This suggests that the ITS region will not be useful to monitor the global spread of diversifying pandemic clones in regions such as Australia.

In light of the limitations of the above markers, we decided to explore moderately and non-tandemly repetitive sequences in the genome of $B d$. Considerable heterogeneity has been identified in association with repetitive regions in other fungal studies. DNA fingerprints using probes for repetitive DNA sequences, including transposons, have been used to identify fungal strains by Southern blotting (Hamer et al. 1989, Levy et al. 1991, Chen \& McDonald 1996). Chen \& McDonald (1996) were able to distinguish 617 different genotypes from 673 isolates of the plant pathogen Mycosphaerella graminicol.

A single pair of primers targeting repetitive sequences can amplify many loci, requiring fewer PCR amplifications and less DNA than the use of multiple single-copy loci. In addition, single strand conformation polymorphism (SSCP) analysis (Orita et al. 1989) provides a powerful method to screen for polymorphisms in amplified DNA sequences, allowing the detection of sequence differences (as little as single base-pair changes) between single-stranded DNA molecules of identical length because these fragments adopt different 3-dimensional conformations during electrophoresis under non-denaturing conditions. Capillary electrophoresis-single strand conformation polymorphism (CE-SSCP) analysis provides a high-throughput approach to SSCP, using DNA sequencers (Zinger et al. 2008). CE-SSCP analysis is more sensitive and provides much better resolution between conformers than gel-based analysis.

Two sequenced genomes of $B d$ are available: strain JEL423 (Panama) (Broad Institute of Harvard and MIT, www.broad.mit.edu) and strain JAM81 (California) (Joint Genome Institute [JGI], US Department of Energy, www.jgi.doe.gov/). We compared these to identify repetitive loci that possessed polymorphisms (indels and substitutions). Specific primers for the amplification of multiple paralogs from repetitive loci were designed and assessed for the presence of polymorphisms using CE-SSCP as a mutation screening system.

\section{MATERIALS AND METHODS}

\section{Marker selection}

Repetitive sequences are common in the $B d$ genome. Tracts of approximately $3000 \mathrm{bp}$ of DNA, annotated as repetitive in the Broad Institute genome sequence (JEL423), were randomly selected and a BLAST search (Broad Institute) performed to identify paralogous fragments from moderately and nontandemly repetitive loci and their genome locations. If >5 matches were obtained, the paralogs were then aligned for the identification of polymorphic regions. Conserved regions that flank the polymorphic sections were used for the design of primers for amplification of fragments of approximately $200 \mathrm{bp}$, an optimal size for SSCP analysis. These fragments were then BLASTed against the genome sequence from JGI (strain JAM81); paralogous sequences were obtained and aligned against those from JEL423 to identify any inter-strain polymorphisms. Three primer pairs, capable in silico of amplifying fragments with inter-strain polymorphisms and targeting widely separated regions in the genome, were chosen for assessment by standard fragment analysis and CE-SSCP analysis and denoted marker systems (MS) 1 to 3.

Three more primer pairs (MS4 to MS6) were developed in a similar manner for assessment by standard fragment analysis (size profile) alone. This was done because preliminary CE-SSCP analysis in one configuration demonstrated poor between-run reproducibility. For MS4 to MS6, fragments of between 400 and $500 \mathrm{bp}$ were targeted. The increased size would provide more information if the marker systems were assessed by next generation sequencing.

\section{$B d$ isolates and field samples}

Five cultured $B d$ isolates, held at James Cook University, Townsville, QLD, Australia, were assessed for inter-strain variability in the initial assessment by fragment and CE-SSCP analysis. The strains, following the naming scheme proposed by Berger et al. (2005) were: Rockhampton-Lcaerulea- 
99-LB-1，Townsville-Lcaerulea-05-LB-1，MtMiseryLrheocola-05-LB-1， Tully-Lrheocola-06-LB-1， and Melbourne-Llesueuri-00-LB-1. Skin swab extracts from 3 infected Australian frogs (2007, SE and N Queensland and Victoria) and 2 uninfected frogs (2007, N Queensland), and 1 infected frog from Indonesia (Rhacophorus javanus, refer to Kusrini et al. 2008) were also used. Eight cultured $B d$ isolates, held at James Cook University, were assessed for inter-strain variability by fragment analysis for MS4 to MS6 and repeat analysis of MS1. The strains included the 5 initially assessed by CE-SSCP plus Tully-Ndayi-98-LB-1, Couta Rocks-Lperonii-09-LB-1, AbercrombieR-Lbooroolongensis-09-LB-1. Skin swab extracts from 2 infected Australian frogs (2007, N Queensland) were also assessed.

\section{DNA extraction and PCR conditions}

DNA was extracted from frog-skin swabs and $B d$ pellets from cultures using Prepman ${ }^{\circledR}$ Ultra sample preparation reagent (Applied Biosystems) as described by Hyatt et al. (2007). Reaction volumes were 15 or $20 \mu \mathrm{l}$. Each reaction included 0.8 units of FastStart Taq DNA polymerase (Roche), $0.25 \mathrm{mM}$ of each dNTP (Invitrogen 10297-018), $900 \mathrm{nM}$ of each primer, $3 \mathrm{mM}$ of $\mathrm{MgCl}_{2}, 400 \mathrm{ng} \mathrm{\mu l}^{-1}$ of BSA (Sigma A4161), and $6.67 \mu \mathrm{l}$ of 1:10 diluted template. PCR amplification incorporated an initial denaturing step of $95^{\circ} \mathrm{C}$ for $4 \mathrm{~min}$, followed by 35 cycles of $95^{\circ}$ for $30 \mathrm{~s}$, then $49^{\circ} \mathrm{C}$ or $52^{\circ} \mathrm{C}$ or $55^{\circ} \mathrm{C}$ for $30 \mathrm{~s}$, and $72^{\circ} \mathrm{C}$ for $45 \mathrm{~s}$. For MS1 to MS3, assessed using both fragment analysis and CE-SSCP, forward primers were fluorescently labeled with 6FAM and each reverse primer was labeled with HEX. (It is necessary to monitor both strands during CESSCP electrophoresis as relative migration rates may vary between alleles represented by the different complementary strands.) For MS4 to MS6, only the forward primer was labeled (with 6-FAM).

\section{Fragment analysis}

Initial standard fragment analysis of MS1 to MS3 (PCR annealing temperature used was $55^{\circ} \mathrm{C}$ ) was undertaken at the Genetic Analysis Facility, James Cook University using a MegaBACE 1000 sequencer (GE) and the ET-400R size standard.

For the second round of assessment, using MS1 and MS4 to MS6, the PCR annealing temperatures were 49 or 52 or $55^{\circ} \mathrm{C}$ and this was followed by a final extension step of $10 \mathrm{~min}$ at $72^{\circ} \mathrm{C}$. Fragment analysis was undertaken at the Australian Genome Research Facility (AGRF), using an Applied Biosystems AB3730 and GS500 size standard.

The robustness of MS1 and MS4 to MS6 was tested by using 2 annealing temperatures for the screening of extracts from the 8 cultured isolates and the 2 frogskin swabs. The annealing temperatures were 52 and $55^{\circ} \mathrm{C}$ for MS1, MS4 and MS5, and 49 and $52^{\circ} \mathrm{C}$ for MS6. Additionally we tested the effect of varying the template concentration by loading 100 zoospore equivalents (ZSE), $10 \mathrm{ZSE}$ and $1 \mathrm{ZSE}$ of extracted DNA (isolate Tully-Lrheocola-06-LB-1) as template for the PCR, using an annealing temperature of $50^{\circ} \mathrm{C}$.

\section{CE-SSCP analysis}

CE-SSCP analysis was performed by the Genome Laboratory, John Innes Centre (JIC), Norwich Research Park, England, and also by the Macquarie Sequencing Facility, Macquarie University (MU), Sydney, Australia. The JIC used a 3730xl Genetic Analyser (Applied Biosystems), and the matrix included 5\% CAP polymer (Applied Biosystems), $4 \mathrm{M}$ urea, $7.5 \%$ sucrose, and $1 \times$ TTE $(90 \mathrm{M}$ tris $\mathrm{pH}$ 9.0, $8.5 \mathrm{mM}$ taurine, $0.5 \mathrm{mM}$ EDTA). Electrophoresis was carried out at $18^{\circ}, 25^{\circ}$, and $30^{\circ} \mathrm{C}$. The inclusion of $4 \mathrm{M}$ urea produces slightly denaturing conditions. These conditions were optimized for conformation-sensitive capillary electrophoresis to detect polymorphisms in double-stranded DNA but were routinely used at JIC for SSCP analysis (D. Baker pers. comm.).

The CE-SSCP analysis performed at MU was carried out on a 3130xl Genetic Analyser (Applied Biosystems) using $7 \% \mathrm{POP}^{\mathrm{TM}}$ Conformation Analysis Polymer and GeneScan ${ }^{\mathrm{TM}} 500$ LIZ ${ }^{\circledR}$ size standard at 20,25 and $30^{\circ} \mathrm{C}$. This matrix is non-denaturing and could potentially increase the number of stable conformers produced between different alleles or paralogs, relative to that obtained using a more denaturing matrix, and therefore has the potential to increase the sensitivity of mutation detection.

\section{RESULTS}

\section{Polymorphisms between JEL423 and JAM81}

Table 1 provides primer sequences, fragment sizes, the number of paralogs having identity or near-identity with primer sequences for strains JEL423 (Broad Institute) and JAM81 (JGI) and the number of unique paralogs/alleles. 
Table 1. Primer sequences, fragment size, number of paralogs, and the number of unique paralogs or alleles in Batrachochytrium dendrobatidis $(B d)$ strains JEL423 and JAM81 for marker systems MS1 to MS6. Fragment sizes unique to one strain are shown in bold. The number of unique paralogs shown in the final column potentially includes alleles

\begin{tabular}{|c|c|c|c|c|c|}
\hline $\begin{array}{l}\text { Marker } \\
\text { system }\end{array}$ & Primer sequences & $\begin{array}{l}\text { Fragment } \\
\text { sizes (bp) }\end{array}$ & $\begin{array}{l}\text { No. of pc } \\
\text { JEL } 423\end{array}$ & $\begin{array}{l}\operatorname{aralogs} \\
\text { JAM81 }\end{array}$ & $\begin{array}{l}\text { No. of unique } \\
\text { paralogs }(\%)\end{array}$ \\
\hline MS1 & $\begin{array}{l}\text { TCA TCA ATG TGT ACA ACT ATG CAA T } \\
\text { TTT GAT TGC TAA TCT GAA CTG GT }\end{array}$ & $\begin{array}{l}205,215,219,228 \\
\quad \mathbf{2 4 1}, 242,247^{\mathrm{a}}\end{array}$ & 9 & 7 & $6(37.5)$ \\
\hline MS2 & $\begin{array}{l}\text { GCA AGC AAA CCA TAC GAG TG } \\
\text { GTA TTG TGC ATT ATG GTT GTT TGA C }\end{array}$ & 217,218 & 14 & 16 & $13(43.3)^{\mathrm{b}}$ \\
\hline MS3 & $\begin{array}{l}\text { TGG AAA TTC CCC AAA CAC AT } \\
\text { TTC TGG ACG AGT GTA TTG CT }\end{array}$ & 197,198 & 12 & 14 & $5(19.2)^{c}$ \\
\hline MS4 & $\begin{array}{l}\text { ATC AGT ATA GTT ACC ATC AAC ACA CTA C } \\
\text { GAA TTT AAT TTT GTT GAT TCG ACT }\end{array}$ & $\begin{array}{r}\mathbf{4 4 1}, \mathbf{4 4 2}, \mathbf{4 5 1}, 453 \\
459, \mathbf{4 6 0}, 465,466 \\
468,469,477, \mathbf{4 7 8} \\
\quad 487, \mathbf{4 8 8}^{\mathrm{d}}\end{array}$ & 26 & 22 & $26(54.2)^{\mathrm{e}}$ \\
\hline MS5 & $\begin{array}{l}\text { AAA GCG TAT GTT ACA ATA GTA AAC TTG } \\
\text { ACT TGA TGG CAA CTA TTA CGA AC }\end{array}$ & $\begin{array}{l}\mathbf{4 8 2}, \mathbf{4 8 3}, \mathbf{4 8 5}, 487 \\
488,489,491,492^{\mathrm{f}}\end{array}$ & 22 & 19 & $23(56.1)$ \\
\hline MS6 & $\begin{array}{l}\text { ATT GGG TGG TTC ATC AG } \\
\text { GAT CGT TTT GAT ATG ACA TTT G }\end{array}$ & $\begin{array}{c}421,424,426, \mathbf{4 2 7} \\
429,431,434, \mathbf{4 3 5} \\
\quad 436,439,441\end{array}$ & 21 & 19 & $17(42.5)^{g}$ \\
\hline \multicolumn{6}{|c|}{ 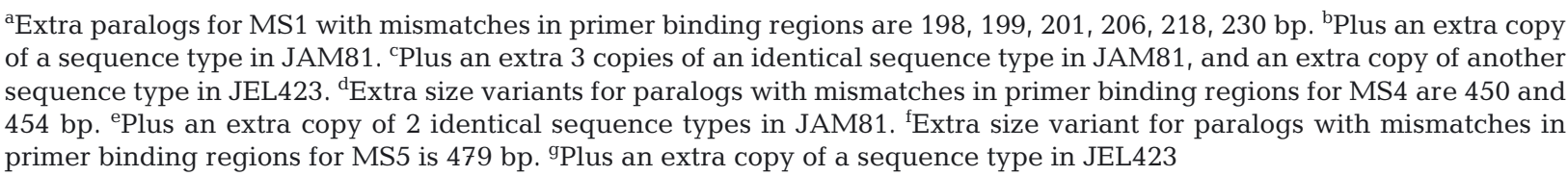 } \\
\hline
\end{tabular}

The number of paralogs/alleles unique to one strain ranged from 6 for MS1 to 26 for MS4, providing evidence for considerable variation in repetitive loci between the 2 strains.

Fig. S1 in the supplement at www-int-res.com/ articles/suppl/d097p001_supp.pdf presents a UPGMA dendrogram which demonstrates the presence of identical, divergent and unique paralogs or alleles in the comparison between the 2 strains for the paralogs of MS5 (data not shown for other MSs)

\section{Fragment analysis and tests of robustness}

MS1 to MS3 amplified sharp, single bands of appropriate size from DNA extracts obtained both from pure cultures and swabs from infected frogs (data not shown). Importantly, no amplification was obtained from extracts from uninfected frogs for any marker system. Fragment analysis on a MegaBACE 1000 sequencer demonstrated the production of the anticipated 205, 215, 219, 228, 241, 242, and
247 bp products for MS1, and in addition a 1 bp stutter may have been produced, probably due to the terminal transferase activity of the polymerase (Fig. 1). An additional 206 bp product was also evident. Note that numerous paralogs, including a 206 bp fragment, are also present in both strains that do not have complete primer identity but may amplify (Table 1). All $B d$ strains produced the same profile except
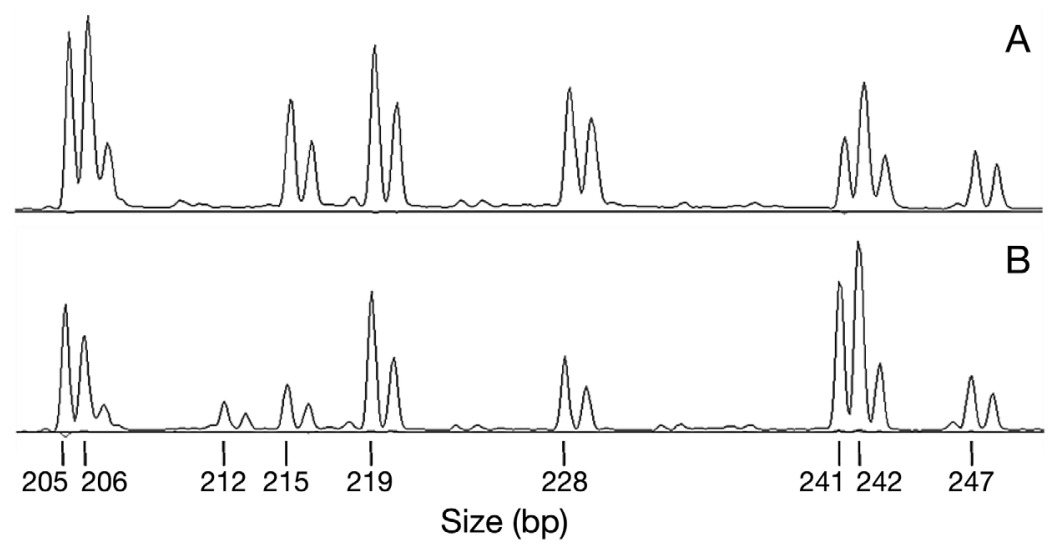

Fig. 1. Fragment analysis of PCR product of Batrachochytrium dendrobatidis $(B d)$ strains for marker system MS1, using a MegaBACE 1000 sequencer (GE) and the ET-400 size standard. (A) Rockhampton-Lcaerulea-99-LB-1. (B) Townsville-Lcaerulea-00-LB-1; the same size profile was produced by strains MtMisery-Lrheocola-05-LB-1, Tully-Lrheocola-06-LB-1, and MelbourneLlesueuri-00-LB-1. Notice the extra product at $212 \mathrm{bp}$ in (B) 
for Rockhampton-Lcaerulea-99-LB-1, which was missing a paralog of $212 \mathrm{bp}$ (Fig 1A).

When run on an Applied Biosystems AB3730 analyser at AGRF, MS1 produced the same fragment profile as previously obtained for each isolate using a MegaBACE 1000. This applied across all annealing temperatures and also for template concentrations of 100 and 10 ZSE (Figs. $2 \& 3$ ). However, extra fragments below $200 \mathrm{bp}$ were produced at the lower annealing temperatures of $50^{\circ} \mathrm{C}$ and $52^{\circ} \mathrm{C}$, indicating that $55^{\circ} \mathrm{C}$ should be used to avoid what is potentially nonspecific amplification

At low template concentrations (1 ZSE) only a subset of fragments were amplified (Fig. 2), suggesting however that at least a subset of paralogs of that size could be reliably amplified from swabs taken from frogs with low levels of infection. Generally speaking, MS1 demonstrated robust results using moderate to high template concentrations, including extracts from skin swabs, and did not vary with changes to annealing temperature except for the amplification of extra, potentially non-specific, products at the lower temperature.

Additionally a further polymorphism was identified representing a lack of a size variant in isolate Couta Rocks-Lperonii-09-LB-1 (Fig. 3C,D). Three genotypes were identified for the 8 Australian isolates based on fragment analysis (sizing) alone.

Fig. 3. Representative results from fragment analysis of extracted Batrachochytrium dendrobatidis $(B d)$ DNA from 7 Australian isolates (not including Rockhampton-Lcaerulea99-LB-1, which produces a different profile, see Fig. 1) and 2 skin swabs from infected frogs using an Applied Biosystems AB3730 analyser and GS500 size standard of marker system MS1 at 2 annealing temperatures. (A) and (B) are the profiles for 6 isolates and 2 skin swabs, represented by one of the skin swabs from north Queensland, produced at annealing temperatures of $52^{\circ} \mathrm{C}$ and $55^{\circ} \mathrm{C}$, respectively. (C) and (D) show results for isolate Couta Rocks-Lperonii-09-LB-1 that lacks a size variant at $241 \mathrm{bp}$ (vertical arrow)

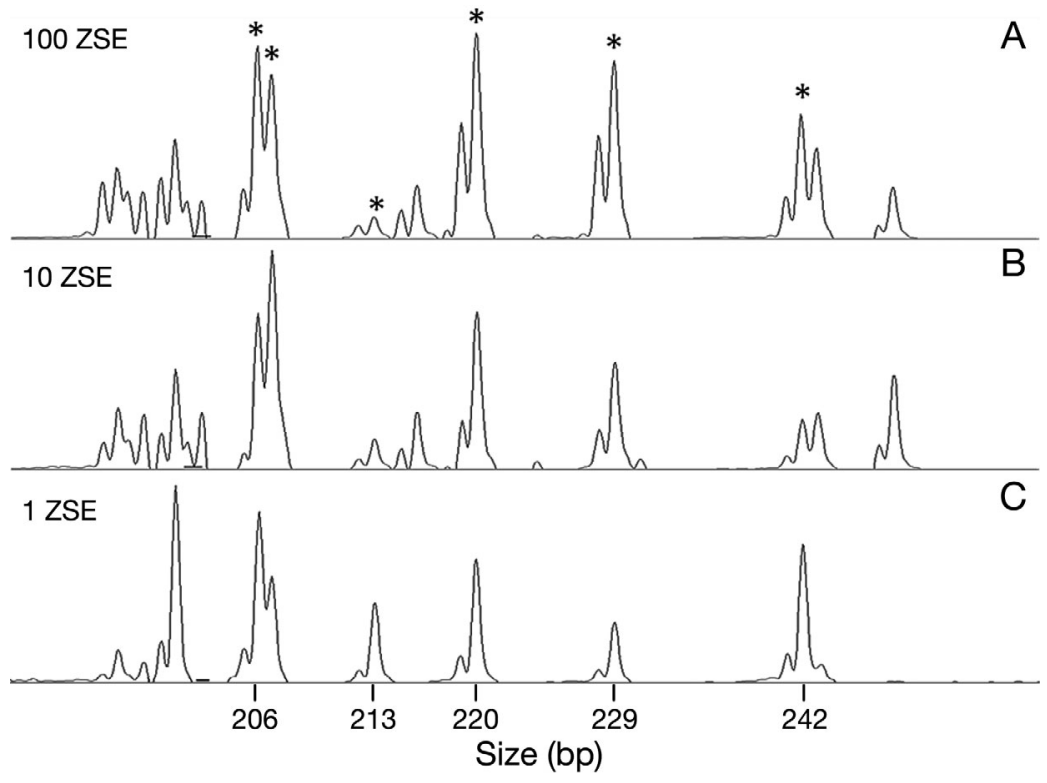

Fig. 2. Results from fragment analysis of extracted Batrachochytrium dendrobatidis (Bd) DNA (isolate Tully-Lrheocola-06-LB-1), using an Applied Biosystems AB3730 analyser and GS500 size standard of marker system MS 1 at an annealing temperature of $50^{\circ} \mathrm{C}$, for 3 template concentrations: (A) 100, (B) 10 and (C) 1 zoospore equivalents (ZSE). (*) Subset of fragments that amplified at all template concentrations used

The only other marker system demonstrating interisolate polymorphism was MS5. This yielded products of the expected size ranging from 478 to $491 \mathrm{bp}$ (Fig. 4). Reproducibility was excellent for template concentrations between 100 and 10 ZSE, between

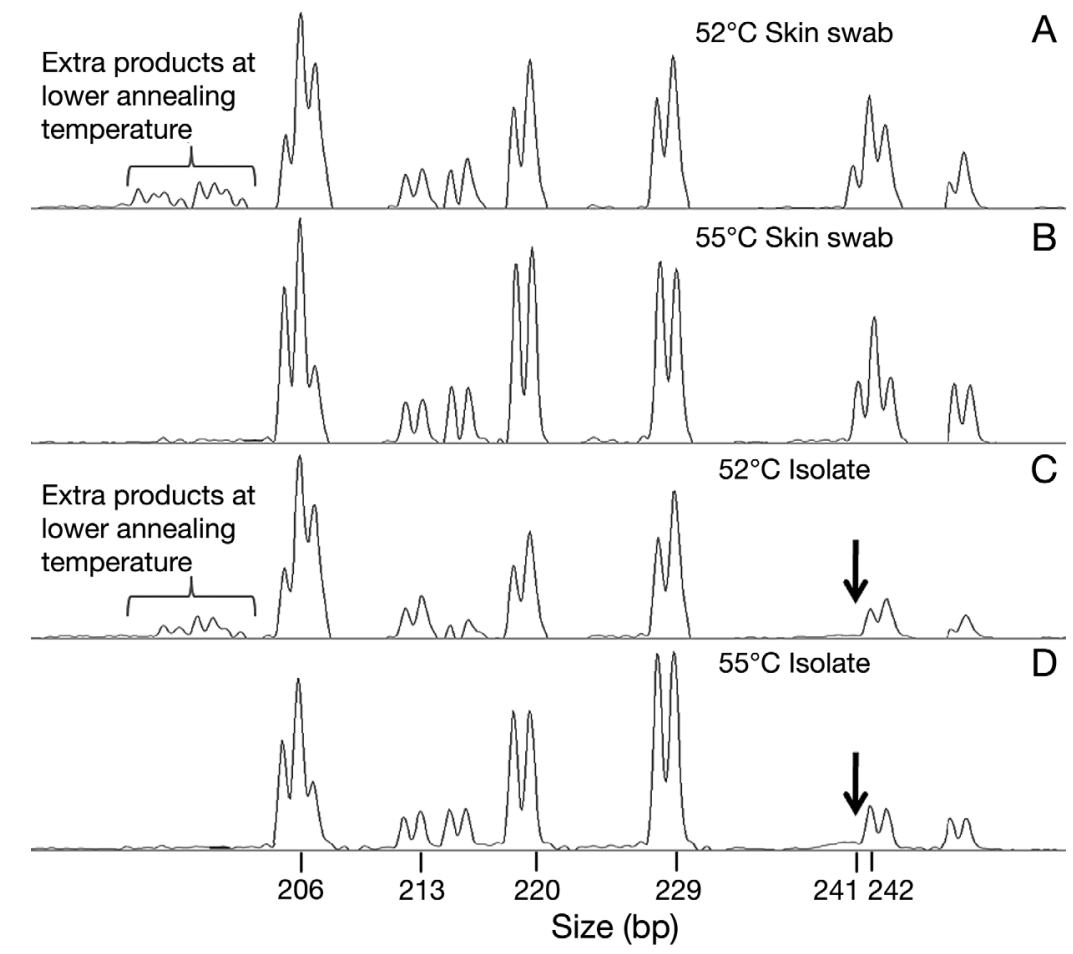




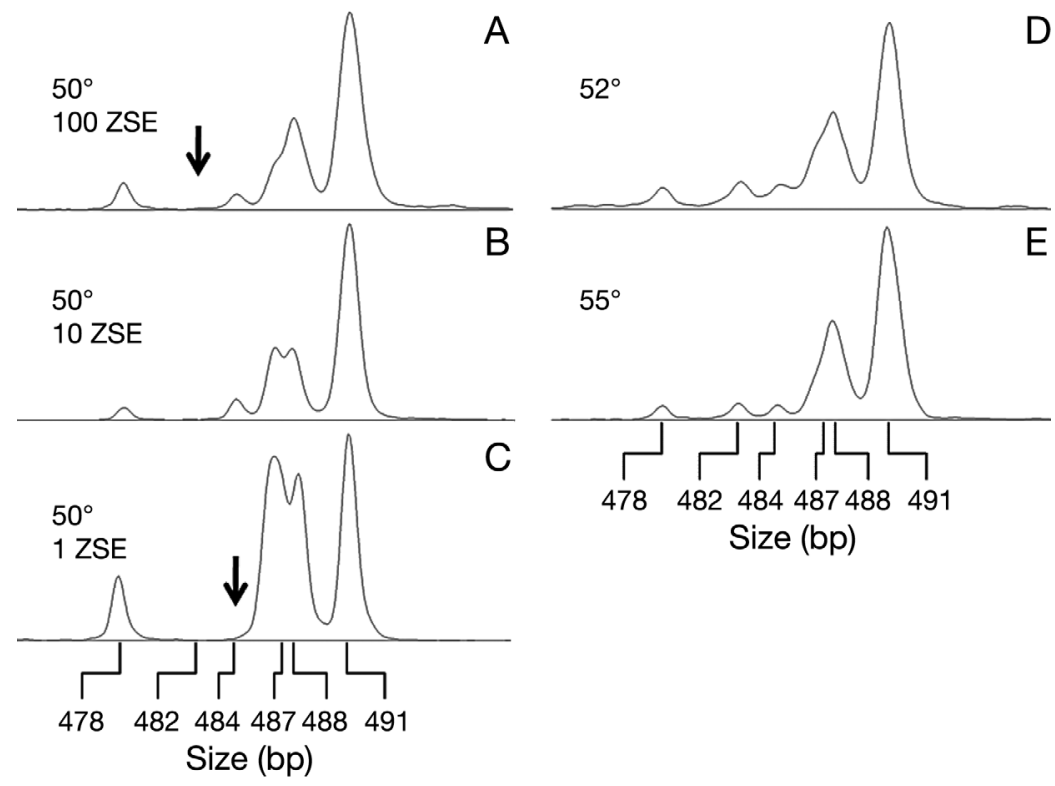

Fig. 4. Effect of different template concentrations and annealing temperatures on results of fragment analysis of extracted Batrachochytrium dendrobatidis $(B d)$ DNA for marker system MS5. (A-C) Results for isolate Tully-Lrheocola06-LB-1 at an annealing temperature of $50^{\circ} \mathrm{C}_{i}$ (A) 100 , (B) 10 and (C) 1 zoospore equivalents (ZSE). Arrow in (A) indicates the lack of the $482 \mathrm{bp}$ size variant (also absent in B, C) in this isolate. The $482 \mathrm{bp}$ variant was observed in all other sample/PCR-condition combinations. Arrow in (C) indicates the failure of the $484 \mathrm{bp}$ size variant to amplify at $1 \mathrm{ZSE}$. (D,E) Representative results for all other sample/PCR-condition combinations, including isolates and skin swabs, at annealing temperatures of (D) $52^{\circ} \mathrm{C}$ and (E) $55^{\circ} \mathrm{C}$
D ment analysis (Fig. 1). The strains Rockhampton-Lcaerulea-99-LB-1 and Townsville-Lcaerulea-00-LB-1 could be uniquely identified from the other 3 isolates that could not be distinguished. Significantly, the DNA extracts from skin swabs of infected frogs produced the same electrophoretic profile as the 3 indistinguishable cultured isolates, MtMisery-Lrheocola05-LB-1, Tully-Lrheocola-06-LB-1, and Melbourne-Llesueuri-00-LB-1. The result for the swab obtained from the infected Indonesian frog was missing a paralog in comparison to all Australian samples (Fig. 5). The ability to identify the same polymorphisms in separate injections, run at different temperatures, demonstrates the robustness and reproducibility of the analysis. For MS2 and MS3, CE-SSCP analysis at JIC did not distinctly separate paralogs (data not shown), noting that for each marker system the paralogs only varied by $1 \mathrm{bp}$ in length.

The CE-SSCP analysis performed at MU, using non-denaturing conditions, increased the number of peaks and annealing temperatures, and between extracts produced from cultures and swabs for at least a subset of paralogs for each size variant (Fig. 4). One size variant was not amplified at 1 ZSE. Tully-Lrheocola-06LB-1 lacked the 482 bp size variant and all other samples produced the same profile. We have therefore demonstrated that 3 of the 8 Australian isolates tested could be distinguished solely by size profiles produced by MS1 and MS5.

MS4 and MS6, while yielding products of the anticipated sizes, did not demonstrate inter-isolate polymorphism. Reproducibility was excellent for template concentrations between 100 and 10 ZSE, between annealing temperatures, and between extracts produced from cultures and swabs for at least a subset of paralogs for each size variant (see Figs. S2 \& S3 in the supplement).

\section{CE-SSCP analysis}

The CE-SSCP analysis at $18^{\circ} \mathrm{C}$ and $25^{\circ} \mathrm{C}$, as performed at JIC under slightly denaturing conditions, identified a further polymorphism for MS1 (Fig. 5) in comparison to the output from standard frag- distinguished different sequence types for the 3 marker systems (as observed for MS1 in Fig. S4 in the supplement) relative to the analysis performed using slightly denaturing conditions (JIC). Paralogs of equal size but different nucleotide sequence produced more conformers with different electrophoretic mobility under the non-denaturing conditions. We found good reproducibility between PCR amplifications and within electrophoresis runs (between capillaries) for MS1, but not between electrophoresis runs (Fig. S4 in the supplement).

However, inter-isolate polymorphisms (loss and gain of peaks) were identified in the CE-SSCP analyses for MS1 (Fig. S5 in the supplement). CE-SSCP analysis at $25^{\circ} \mathrm{C}$ produced the best resolution among Australian isolates with 4 genotypes identified for the 5 cultures tested. Only Tully-Lrheocola-06-LB-1 and Melbourne-Llesueuri-00-LB-1 were identical (Fig. S5 in the supplement).

Putative polymorphisms were identified for MS2 $\left(20^{\circ} \mathrm{C}\right.$, HEX-labelled strand); however, changes to migration patterns between electrophoretic runs confounded the confirmation of differences (data not shown). Polymorphisms were also suspected for MS3. However, further analysis demonstrated poor 


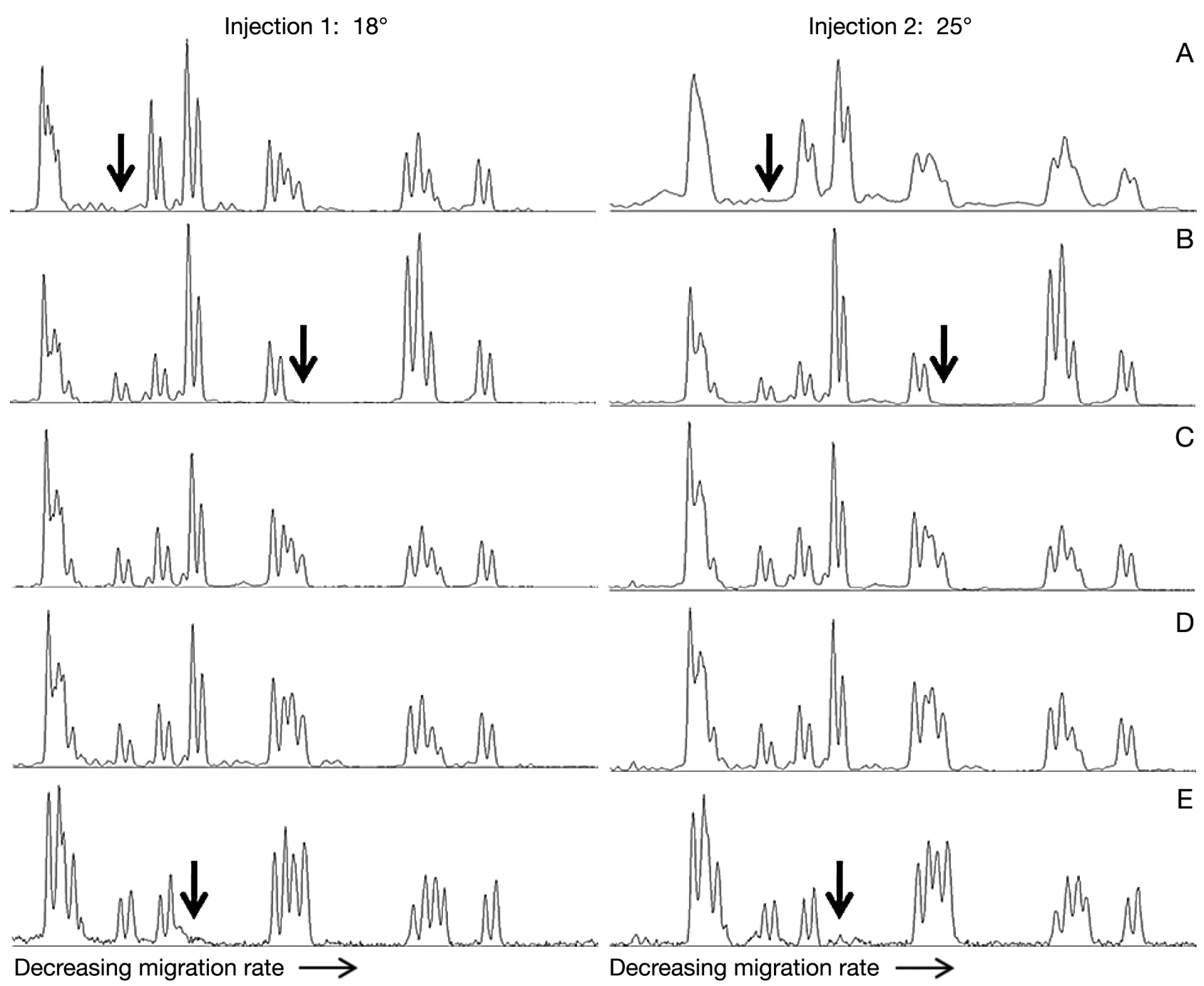

Fig. 5. Electropherograms produced by capillary electrophoresis-single strand conformation polymorphism (CE-SSCP) analysis of the PCR product of Batrachochytrium dendrobatidis $(B d)$ strains for marker system MS1. Performed by the John Innes Centre, England. Results of 2 different injections, run at $18^{\circ} \mathrm{C}$ (left) and $25^{\circ} \mathrm{C}$ (right), are shown. (A) Rockhampton-Lcaerulea99-LB-1. (B) Townsville-Lcaerulea-00-LB-1. (C) MtMisery-Lrheocola-05-LB-1; the same profile was also produced by strains Tully-Lrheocola-06-LB-1 and Melbourne-Llesueuri-00-LB-1. (D) Skin swab from an infected north Queensland frog; the same pattern was obtained from a skin swab from an infected Victorian frog. (E) Skin swab of an infected Indonesian frog. Vertical arrows indicate missing peaks

reproducibility for some of the products between injections within an electrophoretic run (data not shown).

\section{Fragment homologies}

We have identified interesting homology among 4 of the repetitive loci and genes from other species. MS2 is approximately $150 \mathrm{bp}$ from a fragment that is potentially an ortholog of a bacterial transposase (EDY92246.1, 29\% identity, 19/64 amino acids, Expect [E] value 0.10 ). MS1 is $18 \mathrm{bp}$ from a serine- rich region in $B d$ that is very similar to Epa5p (AAQ82687, 1, 37\% identity, 31/83 amino acids, E value 0.0002$)$, a paralog of Epa1 which is a virulencerelated surface glycoprotein from the yeast pathogen Candida glabrata (De Las Peñas et al. 2003). The EPA genes are a large family of glycosylphosphatidylinositol-anchored cell wall proteins, found in diverse fungal species, and Epa1 is involved in adherence to host cells (De Las Peñas et al. 2003).

The fragments amplified by MS3 and MS5 are potentially orthologs of the Crinkler (CRN) gene family (MS3-EEY55054.1, $41 \%$ identity, 28/68 amino acids, E value 0.002; MS5-XP002896589.1, $31 \%$ 
identity, 22/71 amino acids, E value 0.85) from the oomycete plant pathogen, Phytophthora infestans (Torto et al. 2003). The Crinkler proteins are extracellular effector proteins that can elicit a defence response in tomato (Torto et al. 2003) and therefore may be associated with virulence in $B d$.

\section{DISCUSSION}

In order to understand the origins, patterns of spread and population genetics of $B d$, an emerging pathogen with low genetic diversity, highly polymorphic markers must be identified. Current approaches using multi-locus sequence-typing of single-copy nuclear loci do not provide such markers. Many single-copy loci would need to be screened, requiring many PCR amplifications and therefore quantities of DNA template that can only be obtained from pure $B d$ cultures. The need for more efficient (few PCR amplifications) and polymorphic marker systems that require less DNA is particularly urgent in chytridiomycosis research to facilitate use of pathogen DNA from skin swabs from living amphibians. Markers other than single-copy nuclear loci therefore need to be identified.

Because of the reported very low allelic diversity of microsatellites in $B d$, we assessed repetitive sequences which facilitate the analysis of numerous loci in single PCR amplifications. Repetitive regions of fungal genomes are known to be heterogeneous (Hamer et al. 1989, Levy et al. 1991, Chen \& McDonald 1996). Similarly, our initial investigations confirmed that polymorphisms were associated with repetitive loci, as targeted by our marker systems, in the comparison of $2 \mathrm{Bd}$ genome sequences.

We subsequently confirmed the existence of differences between Australian isolates and an Indonesian isolate for one marker system and between Australian isolates for another. In addition, the reproducible CE-SSCP analysis performed at JIC for MS1 could distinguish between 2 closely related Australian isolates, Melbourne-Llesueuri-00-LB-1 and Townsville-Lcaerulea-05-LB-1. James et al. (2009) could not separate these 2 isolates in the comparison of 17 nuclear SNP loci. Three of 8 isolates could be distinguished based solely on the size profiles of amplified paralogs from 2 repetitive loci (MS1 and MS5).

Our CE-SSCP results, using non-denaturing conditions, suggested that further polymorphisms are present for MS1. Given the level of variability observed in the comparison between the 2 sequenced genomes and our empirical evidence for MS1 and MS5, all of the loci and primer-pairs presented here are likely to be useful in genetic studies. Importantly, we confirmed that $B d$-specific primers can work on extracts from skin swabs from moderately to highly infected frogs rather than from pure cultures which are laborious to obtain. With this increased efficiency more samples, many already collected during disease surveys, can be easily tested.

The marker systems developed here are currently not optimal for differentiating strains, and further work is also needed to develop sensitive and reproducible CE-SSCP protocols for analysing the fragments of these markers produced by PCR. However, next-generation sequencing could offer a potential analysis method, fully describing sequence variants for a sample and the relative loss or gain of unique markers between samples. This technology could be used to sequence pooled amplifications from multiple primer pairs for multiplexed samples producing a sensitive and efficient genotyping system. Alternatively, the preliminary results obtained from the CESSCP analysis suggests that further optimization of the levels of denaturant in the matrix (intermediate between the 2 methods tested in this study) may provide the needed resolution to separate sequence variants and provide good between-run reproducibility. CE-SSCP could offer a cost-effective system especially for small studies and for low throughput analysis.

Given that putative EPA-associated and Crinkler paralogs are polymorphic, these genes may be associated with differences in virulence which has been seen among some strain-host interactions (Berger et al. 2005). The polymorphism and copy number variation of these genes should be assessed in investigations attempting to identify virulence factors or the genetic basis for virulence differences among strains.

Acknowledgements. Thanks to the anonymous reviewers for constructive comments and M. D. Kusrini, Bogor Agricultural University, Bogor, Indonesia, for supply of the Indonesian sample. This study was made possible due to funding from the Australian Government Department of the Environment, Water, Heritage and the Arts and James Cook University.

\section{LITERATURE CITED}

Berger L, Marantelli G, Skerratt LF, Speare R (2005) Virulence of the amphibian chytrid fungus Batrachochytrium dendrobatidis varies with the strain. Dis Aquat Org 68: 47-50

Chen RS, McDonald BA (1996) Sexual reproduction plays a major role in the genetic structure of populations of the 
fungus Mycosphaerella graminicola. Genetics 142: 1119-1127

De Las Peñas A, Pan SJ, Castaño I, Alder J, Cregg R, Cormack BP (2003) Virulence-related surface glycoproteins in the yeast pathogen Candida glabrata are encoded in subtelomeric clusters and subject to RAP1- and SIRdependent transcriptional silencing. Genes Dev 17: 2245-2258

Goka K, Yokoyama J, Une Y, Toshiro K and others (2009) Amphibian chytridiomycosis in Japan: distribution, haplotypes and possible route of entry into Japan. Mol Ecol $18: 4757-4774$

Hamer JE, Farrall L, Orbach MJ, Valent B, Chumley FG (1989) Host species-specific conservation of a family of repeated DNA sequences in the genome of a fungal plant pathogen. Proc Natl Acad Sci USA 86:9981-9985

Hyatt AD, Boyle DG, Olsen V, Boyle DB and others (2007) Diagnostic assays and sampling protocols for the detection of Batrachochytrium dendrobatidis. Dis Aquat Org 73:175-192

James TY, Litvintseva AP, Vilgalys R, Morgan JA and others (2009) Longcore JE rapid global expansion of the fungal disease chytridiomycosis into declining and healthy amphibian populations. PLoS Pathog 5:e1000458

Kusrini MD, Skerratt LF, Garland S, Berger L, Endarwin W (2008) Chytridiomycosis in frogs of Mount Gede Pangrango, Indonesia. Dis Aquat Org 82:187-194

Levy M, Romao J, Marchetti MA, Hamer JE (1991) DNA fingerprinting with a dispersed repeated sequence resolves

Editorial responsibility: Alex Hyatt, Geelong, Victoria, Australia pathotype diversity in the rice blast fungus. Plant Cell 3: 95-102

Morehouse EA, James TY, Ganley ARD, Vilgaly R, Berger L, Murphy PJ, Longcore JE (2003) Multilocus sequence typing suggests the chytrid pathogen of amphibians is a recently emerged clone. Mol Ecol 12:395-403

> Morgan JAT, Vredenburg VT, Rachowicz LJ, Knapp RA and others (2007) Population genetics of the frog-killing fungus Batrachochytrium dendrobatidis. Proc Natl Acad Sci USA 104:13845-13850

Orita M, Suzuki Y, Sekiya T, Hayashi K (1989) Rapid and sensitive detection of point mutation and DNA polymorphisms using polymerase chain reaction. Genomics 5: 874-879

Pounds JA, Bustamante MR, Coloma LA, Consuegra JA and others (2006) Widespread amphibian extinctions from epidemic disease driven by global warming. Nature 439: 161-167

Skerratt LF, Berger L, Speare R, Cashins S and others (2007) The spread of chytridiomycosis has caused the rapid global decline and extinction of frogs. EcoHealth 4:125-134

> Torto TA, Li S, Styer A, Huitema E and others (2003) EST mining and functional expression assays identify extracellular effector proteins from the plant pathogen Phytophthora. Genome Res 13:1675-1685

Zinger L, Gury J, Alibeu O, Rioux D and others (2008) CESSCP and CE-FLA, simple and high-throughput alternatives for fungal diversity studies. J Microbiol Methods 72 : $42-53$

Submitted: February 23, 2010; Accepted: July 18, 2011 Proofs received from author(s): October 16, 2011 